\title{
List of documents issued by the Conference of European Statisticians (July 1980-June 1981)
}

Copies of the documents listed can be obtained from the Statistical Division of the ECE, Palais des Nations, CH-1211 Geneva 10. Documents are generally available in English, French and Russian.

- Matters arising from the thirty-sixth session of the Economic Comission for Europe (CES/441)/

- Matters arising from the discussion and decisions of the twenty-first session of the Statistical Comission (CES/442).

- The problems of presentation, publication and dissemination of data (CES/443).

- Canadian experience and approaches in the effective dissemination of statistical data (CES/443/Add.1).

- Problems of presentation, publication and dissemination of data - the publishing system in Norway (CES/443/Add.2).

- Publication and dissemination of data (CES/443/Add.3).

- Demand for and dissemination of general information statistics (CES/443/Add.5).

- Possibilities of concurrent implementation of sample surveys with complete enumarations - Turkish experience (CES/444).

- Possibility of replacing exhaustive statistical surveys by sample surveys (CES/444/Add.1).

- On possibilities of replacing complete surveys by samples (CES/444/Add.2).

- Advantages and disadvantages in the replacement of exhaustive statistical investigations by sampling surveys (CES/444/Add.3).

- Statistical activities under the programmes of the subsidiary bodies of the Economic Commission for Europe in 1980/81 and programme of work for 1981/82 (CES/445).

- Statistical activities of international organizations in Europe (CES/446 plus 6 addenda).

- Progress report on the activities of the Computing Research Centre Bratislava in 1980 (CES/447).

- Report on the activity of the International Computer Education and Information Centre in 1980 (CES/448). 
- Progress report on work on the framework for social and demographic statistics (FSDS) (CES/449).

- Comparison of the national accounts and balances of France and Hungary (CES/451).

- Finalization of the conversion key between SITC and SFTC (CES/452).

- National overall energy balances for 1978 and 1979 (CES/453).

- Definitions to be used in conjunction with overall energy balances (CES/454).

- Framework for environmental statistics (CES/455).

- Statistics on water use and quality of water (CES/456).

- Revision of the ICP plans for the years 1981-82 (CES/457).

- Programme of work for 1981/82-1985/86 (CES/458).

- Report of the twenty-ninth plenary session (ECE/CES/18).

- National reports on the use of generalized programs for statistical data processing (CES.WP.9/176 plus nine addenda).

- Draft directory of Generalized Computer Programs (CES/WP.9/177 plus two addenda).

- Report on the computer aspects of the use of registers in statistical offices (CES/WP.9/178).

- National reports on the creation and development of automated data banks (CES/WP.9/179) plus addendum).

- Some aspects of an integrated statistical computing environment (CES/WP.9/180).

- Distributed processing in a centralized statistical system (CES/WP.9/181).

- Some experiences of using a mass storage system in statistical data processing (CES/WP.9/182).

- Experiences in using APL in the statistical service in Finland (CES/WP.9/183).

- End-user languages of the central and regional statistical data bases (CES/WP.9/184).

- Experiences with APL in the services of the Commission of the European Communities (CES/WP.9/185).

- Use of ARGOSS-C language at the INSEE (CES/WP.9/186).

- Data processing aspects of the Hungarian population and housing census of 1980 - considerations and experiences (CES/WP.9/187).

- Data processing aspects of the 1978 national population census in Poland (CES/WP.9/188).

- Experiences in using a central data bank (CDB) and regional data bank (RDB) in a statistical information system (CES/WP.9/189).

- Report of the seventeenth session of the Working Party on Electronic Data Processing held in Geneva, 18-22 May 1981 (CES/WP.9/190).

- Draft guide to energy statistics published by the ECE, the OECD and the SOEC (CES/AC.32/20).

- Statistical information needed for an adequate assessment of energy conservation efforts (CES/AC/32/21).

- Classificatory needs in the field of energy statistics (CES/AC.32/22).

- Overview of energy price and value statistics as currently published in national 
statistical yearbooks (CES/AC.32.23).

- Energy price indices: definitions and methods (CES/AC.32/25).

- Methodological problems involved in the development of statistics on the production and use of black liquor (CES/AC.32/26).

- Methodology of statistics on energy production and use (CES/AC.32/27).

- Methodological problems of developing the statistics on the production and use of thermal waters of low $\left(30-100^{\circ} \mathrm{C}\right)$ temperature with special regard to the utilization of the geothermal energy content of thermal waters in Hungary (CES/AC.32/29).

- Production and utilization of high-temperature geothermal energy statistical data-processing methodology (CES/AC.32/30).

- Development of statistics on the use of firewood in Sweden (CES/AC.32/31).

- Development of science and technology statistics to measure the international flow of technology (CES/AC.33/28 plus addendum).

- The adequacy of statistics on patents as partial indicators of technology flows (CES/AC.33/29).

- Measurement of the economic effects resulting from the implementation of the results of $\mathrm{R}$ and $\mathrm{D}$ (CES/AC.33/30).

- Progress made in the development of international statistics on science and technology (CES/AC.33/32).

- UNESCO efforts in developing international statistics on scientific and technological information and documentation (STID) activities (CES/AC.33/33).

- The measurement of human and financial resources for $R$ and $D$ in the productive sector (CES/AC.33/34).

- Report of the fourth joint meeting on the Development of Science and Technology Statistics held in Geneva 4-7 May 1981 (CES/AC.33/35).

- Summary and discussion of the comments received on 'Guidelines for presentation of the quality of statistics' (CES.AC.48/13).

- Practice and experiences of the Hungarian household budget survey (CES/AC.48/14).

- Use of rotating sampling schemes in household budget surveys in Bulgaria (CES/AC.48/15).

- The non-response problem in the Netherlands (CES/AC.48/16).

- Precision for various estimators for simple random and single-stage cluster samples (CES/AC.48/17).

- Spanish experience on the estimation of some components of the total error (CES/AC.48/18).

- The methods, organization and evaluation of sample surveys of the population in Czechoslovakia (CES /AC.48/19).

- Family budget surveys in Poland (CES/AC.48/20).

- Treatment of non-response in Finland (CES/AC.48/21).

- A survey of non-response terms (CES/AC.48/22).

- Several evaluation procedures used in Spanish population surveys (CES/AC.48/23). 
- Problems of non-response in the Federal Republic of Germany's microcensus (CES.AC.48/24).

- Household surveys in Great Britain (CES/AC.48/25).

- Current household survey (CES/AC.48/26).

- Causes and treatment of incomplete data in household surveys (CES/AC.48/27).

- The experience of Italy in the evaluation of data recorded during family budget surveys (CES/AC.48/28).

- Some methods for evaluating non-sampling error in household censuses and surveys (CES/AC.48/29).

- Report of the meeting on Problems relating to Household Surveys (Statistical methodology) held in Geneva 1-4 June 1981 (CES/AC.48/30).

- Draft recommendations concerning compilation of current population estimates (CES/AC.54/2).

- Draft guidelines on age-group classifications (CES/AC.54/3).

- Co-ordination of statistics of households and families (CES/AC.54/4).

- Report of the meeting on the Co-ordination of Demographic Statistics within the FSDS held in Geneva, 24-27 November 1980 (CES/AC.54/5).

- Report of the Seminar on Environmental Statistics Warsaw, 16-19 September 1980 (CES/SEM.12/2).

- Economic analysis and ensuring the reliability of reported data for environmental records in the Byelorussian SSR (CES/SEM.12/R.1).

- Data collection techniques on the living environment in Czechoslovakia (CES/SEM.12/R.2).

- Data collection techniques (CES/SEM.12/R.3).

- Point sampling in Norwegian land use and environmental statistics (CES/SEM.12/R.4).

- Requirements for the practical application of procedures and techniques ensuring the availability of statistical information on the natural environment in Poland (CES/SEM.12/R.5).

- Techniques of data collection in the context of identification and control of environmental impact (CES/SEM.12/R.6).

- System of indicators and collection from enterprises and institutions of data on the protection of human environment in the USSR (CES/SEM.12/R.7).

- Towards a spatial base for a national system of environmental statistics based upon aggregations of local government areas - recent Australian experience (CES/SEM.12/R.8).

- Relationship between monitoring and survey data (CES/SEM.12/R.9).

- Implementation of classification and nomenclatures for environmental statistics (CES/SEM.12/R.11).

- Economic aspects of environmental activities, especially in the industrial sector (CES/SEM.12/R.12).

- Social concerns and the system of environmental statistics (CES/ SEM.12/R.13). 
- The use of environmental data in the economic decision-making process (CES/SEM.12/R.14).

- Questions of co-ordination between national bodies involved in the collection and compilation of environmental statistics (CES/SEM.12/R.15).

- Issues and experiences in the development and co-ordination of environmental statistics in Norway (CES/SEM.12/R.16).

- Report of the Seminar on Integrated Statistical Information Systems and Related Matters (ISIS '80) Bratislava, Czechoslovakia 22-26 September 1980 (CES/SEM.13/2).

- Present state of development and use of the data base for the State Central Office of Statistics in the German Democratic Republic - January 1980 (CES/SEM.13/R.1).

- The structure and realization of the data system and data management (CES/SEM.13/R.2).

- The structure and content of the statistical data base in the Hungarian Central Statistical Office (CES/SEM.13/R.3).

- Summary of the Aero Project: Results and experiences (CES/SEM.13/R.4).

- The construction and use of standard names in table production and indexing (CES/SEM.13/R.5).

- A table generator for hierarchically structured data (CES/SEM.13/R.6).

- Principal features of the Federal Statistical Office's data base (Yugoslavia) (CES/SEM.13/R.7).

- SOAPOI - programmed system for estimaing operational expenditure on statistical data processing (CES/SEM.13/R.8).

- Semantic modelling in Statistics Canada (CES/SEM.13/R.9).

- Relevance of and problems related to the establishment of the Central Statistical Data Bank (CES/SEM.13/R.10).

- Progress report on the construction of the ASIS meta data base and the main spheres of its' use (CES/SEM.13/R.11).

- Comments on the present state of data base systems (CES/SEM.13/R.12).

- A suggested structure for the projected data base of the statistical information system on construction in Czechoslovakia (CES/SEM.13/R.13).

- Semantic structures of meta-data in the statistical information system (CES/SEM.13/R.14).

- Report on GKOS, a data base management system development by the Austrian Central Statistical Office (CES/SEM.13/R.15).

- Meta-data management system for official statistics in Italy (CES/SEM.13/R.16).

- The data base and meta-information for an on-line statistical data processing system (CES/SEM.13/R.17).

- Distributed data processing in the state statistics (CES/SEM.13/R.18).

- Report on the application and development of the user-oriented sub-system of the statistical information system (CES/SEM.13/R.19).

- SOFIS progress report (CES/SEM.13/R.20).

- An approach to computer-aided data bank design (CES/SEM.13/R.21). 